\title{
Using Bayesian Belief Networks to assess the influence of landscape connectivity on ecosystem service trade-offs and synergies in urban landscapes in the UK
}

\author{
James D. Karimi (D) Jim A. Harris • Ron Corstanje
}

Received: 6 January 2021 / Accepted: 23 July 2021 / Published online: 5 August 2021

(C) The Author(s) 2021

\begin{abstract}
Context Landscape connectivity is assumed to influence ecosystem service (ES) trade-offs and synergies. However, empirical studies of the effect of landscape connectivity on ES trade-offs and synergies are limited, especially in urban areas where the interactions between patterns and processes are complex.

Objectives The objectives of this study were to use a Bayesian Belief Network approach to (1) assess whether functional connectivity drives ES trade-offs and synergies in urban areas and (2) assess the influence of connectivity on the supply of ESs.

Methods We used circuit theory to model urban bird flow of $P$. major and $C$. caeruleus at a $2 \mathrm{~m}$ spatial resolution in Bedford, Luton and Milton Keynes, UK, and Bayesian Belief Networks (BBNs) to assess the sensitivity of ES trade-offs and synergies model outputs to landscape and patch structural
\end{abstract}

Supplementary Information The online version contains supplementary material available at https://doi.org/10.1007/ s10980-021-01307-6.

J. D. Karimi $(\bowtie)$ · J. A. Harris · R. Corstanje

School of Water, Energy, and the Environment, Cranfield

University, Cranfield, Bedfordshire MK43 0AL, UK

e-mail: James-dariush.Karimi@cranfield.ac.uk

J. A. Harris

e-mail: j.a.harris@cranfield.ac.uk

R. Corstanje

e-mail: roncorstanje@cranfield.ac.uk characteristics (patch area, connectivity and bird species abundance).

Results We found that functional connectivity was the most influential variable in determining two of three ES trade-offs and synergies. Patch area and connectivity exerted a strong influence on ES tradeoffs and synergies. Low patch area and low to moderately low connectivity were associated with high levels of ES trade-offs and synergies.

Conclusions This study demonstrates that landscape connectivity is an influential determinant of ES tradeoffs and synergies and supports the conviction that larger and better-connected habitat patches increase ES provision. A BBN approach is proposed as a feasible method of ES trade-off and synergy prediction in complex landscapes. Our findings can prove to be informative for urban ES management.

Keywords BBN - Trade-offs and synergies · Ecosystem services · Connectivity · Urban · Model · Circuit theory

\section{Introduction}

Ecosystem services are the benefits that humans directly or indirectly receive from the ecosystem (Costanza et al. 1997). Interactions among ecosystem services may be either due to simultaneous response to the same driver of change or due to true interactions among services (Bennett et al. 2009). Ecosystem 
service trade-offs arise when the provision of one service is reduced as a consequence of increased use of another service (Rodríguez et al. 2006), and ecosystem service synergies arise when multiple ecosystem services are enhanced simultaneously. Human activities such as intensified land use and fragmentation are modifying land cover and land use patterns, altering landscape structure and ecosystems, and affecting connectivity. Landscape connectivity refers to the degree to which the landscape facilitates or impedes the flow of species and materials across the landscape and results from the interaction between landscape structure and function (Leitão et al. 2006). Changes to landscape structure can affect the movement of species and materials which affect the provision of ESs.

Understanding the importance of landscape connectivity may be important for predicting how land use affects ES provision. Connectivity is relevant in land conservation plans and management. In landscape ecology, landscape connectivity includes concepts such as structural and functional connectivity. The former is related to landscape structure and is a physical attribute of a landscape (e.g. the spatial configuration of land cover types or habitats) and is usually measured using landscape metrics such as patch size, isolation and distance between patches. Functional connectivity is organism-orientated, where behavioural responses are interpreted to suggest whether landscape patches function as connected from the perspective of the organism (LaPoint et al. 2015). Functional connectivity is determined by the flow of organisms across the landscape and by the responses of organisms to landscape structure. The term connectivity includes both biotic connectivity (the movement of organisms) and abiotic connectivity (the movement of matter). References to connectivity in this paper are to functional connectivity of species hereafter, unless otherwise stated.

Urban green space provides ecosystem services such as carbon sequestration, climate regulation, and benefits to nearby residents. Studies have shown that human interactions with green space provide psychological well-being and a sense of connectedness to nature (Cox et al. 2017). Urban features influence structural and functional connectivity (Cox et al. 2016; Grafius et al. 2019). Cox et al. (2016) found that vegetation cover increases connectivity and influences the movement of songbirds. Functional connectivity can be promoted by structural components. However, landscape connectivity is altered by changes in land cover and land use, including habitat fragmentation. Fragmentation is assumed to reduce the provision of multiple ESs and alter landscape connectivity. Modelling and conceptual work by Mitchell et al. (2015b) have found that the highest levels of ES provision is predicted to peak at intermediate levels of natural land cover loss and of habitat fragmentation (Mitchell et al. 2015a). Patch area and patch isolation of natural land cover have been found to have both positive and negative effects on ESs with changes to distance from patch affecting service provision (Mitchell et al. 2014).

Evidence suggests that decreased landscape connectivity usually has negative effects on regulating services such as pollination, pest control, and food provision (Mitchell et al. 2013). Theory suggests that different ESs are likely to respond either positively or negatively to landscape connectivity change, creating and modifying trade-offs and synergies between services. Changes in connectivity, whether decreasing as a result of clearing for urban expansion, or increasing as a result of restoration and conservation, may have both positive and negative effects on ESs through complex interactions with different species and processes (Mitchell et al. 2013; Maguire et al. 2015). In a literature review, provisioning and regulating services were found to be the most widely studied services affected by biotic and abiotic connectivity (Mitchell et al. 2013). For example, retaining non-crop habitat patches near cropland areas increases both pollination and pest regulation services, which in turn increases crop production. As regards to ES provision related to the movement of matter, a decrease in the rate of water flow through riparian buffers from upland areas might increase pollutant filtration and water quality regulation, but decrease water provision downstream (Mitchell et al. 2013).

Functional connectivity can be represented by depicting the movements of urban bird flows using circuit theory. In this paper, we model functional connectivity and the habitat structure of urban great tits (Parus major) and blue tits (Cyanistes caeruleus) which represent typical woodland species adapted to UK urban environments. Land use and land cover types are providers of ecosystem services. For example, woodlands provide a high number of services such as climate regulation, pollination, habitat quality, 
erosion control, water supply and nutrient retention. In this study, modelled urban bird flows were used as a proxy for woodlands and associated ESs. Urban landscapes with high functional connectivity (i.e. with a high tree cover) can supply multiple ESs.

ESs in urban areas provide benefits such as water flow regulation, air purification, noise reduction, pollination and seed dispersal and air temperature regulation (Gómez-Baggethun and Barton 2013). In this research, we test the influence of landscape and patch structural characteristics (patch area and connectivity) on ES trade-off and synergy predictions to assess whether connectivity drives trade-offs and synergies between ecosystem services. Landscape connectivity may influence the magnitude and distribution of ESs. Land use and land cover change can alter landscape connectivity and may result in changes to ecosystem services. Different ecosystem services respond differently to connectivity and create tradeoffs and synergies between services, as landscape structure and human land use are altered and affect ES provision. These trade-offs and synergies may create bundles of ecosystem services that act in similar or dissimilar ways as connectivity is changed, influenced by landscape connectivity and human land use patterns. Thus, connectivity can have either positive or negative effects on service flow depending on the service in question, the process of landscape fragmentation, and the resulting landscape structure. Moreover, connectivity is assumed to affect the provision of ESs not only directly through the flow of species and matter, but also indirectly by altering the levels of biodiversity and ecosystem functions that contribute to ES provision (Mitchell et al. 2013). Increasing connectivity therefore may enhance the supply of ESs and affect biodiversity in urban areas. Landscape connectivity could act as a bridge between biodiversity and ecosystem services. $\mathrm{Ng}$ et al. (2013) assumed that if a habitat within a landscape has a more significant role in connecting with other habitats, it would have a higher ecosystem service value for biodiversity conservation.

The development of blue-green infrastructure in cities is considered to be a suitable approach to improve the function of green space in urban areas. Maintaining and establishing connectivity between patches is essential in facilitating biodiversity conservation. Blue-green infrastructure provides goods and services and could be a solution to intensified land use and fragmentation. Connectivity refers to the structure (i.e. the presence or absence of links (e.g. ecological corridors) between components or nodes (e.g. habitats) and how links are distributed in a network) and extent to which (strength) resources, species and matter migrate or interact across habitats (Dakos et al. 2015). It has been found that habitat network structure is important for biodiversity and to the resilience of a wide range of ESs and their productivity, for example provisioning and regulating services (Chisholm et al. 2011; Thompson et al. 2017). An interconnected network of greenspaces is thought to provide associated benefits to human populations (Lafortezza et al. 2013). Meta-ecosystem and ecological network theories (spatial-insurance hypothesis) suggest that connectivity is important for maintaining biodiversity and improve ES provision. Landscapes that are structurally and functionally connected are thought to be more resilient compared to systems where components are isolated. High levels of connectivity can facilitate recovery after a disturbance. At the same time, highly connected systems increase the potential for disturbances to spread. Therefore, moderate levels of connectivity are likely best for maintaining resilience (Dakos et al. 2015; Field and Parrott 2017). The effect of connectivity on ES provision is context dependent.

There is little empirical evidence that connectivity affects multiple ESs. Urban form has been found to affect the provision of ESs with high-urban development density associated with poor environmental performance, as measured by green patch size and provision of ESs (Tratalos et al. 2007). Environmental quality is related to vegetation structure and the provision of ESs. This study presents a novel approach to assess the sensitivity of ES trade-offs and synergies to connectivity and urban habitat structural features.

In this study, we used a Bayesian Belief Network (BBN) modelling method for predicting ES trade-offs and synergies and used it to test the relationships between urban habitat structural features and ES tradeoffs and synergies. The objectives of this study were to use a BBN modelling approach (1) to assess whether functional connectivity drives ES trade-offs and synergies in urban areas and (2) assess the influence of connectivity on the supply of ESs. We hypothesized that connectivity affects ES trade-offs and synergies and the provision of ESs and that high landscape connectivity increases the supply of ESs. 


\section{Methods}

Study area

The study area was the combined built-up areas of three large UK towns; Milton Keynes, Bedford, and Luton/Dunstable (Fig. 1). Collectively taken as a single study area, the three towns encompass a broad range of urban forms and histories representing much of the diversity found across the UK's urban landscapes. In this study, the three towns were considered an extension of a continuum of an urban form and the data was combined. This approach allows the results to be more widely applicable to other urban areas across the UK, giving this study a greater relevance than a study of a single location would have.

Milton Keynes is a planned 'new town' developed during the $1960 \mathrm{~s}\left(52^{\circ} 00 \mathrm{~N}, 0^{\circ} 470 \mathrm{~W}\right)$, noteworthy for its unique spatial configuration. The town is structured around a grid of major roads designed for speed and ease of automotive travel, rather than the radial pattern common to many more historic English urban landscapes (Peiser and Chang 1999). The town is also characterised by large areas of public green space, possessing many parks and wooded foot and cycle paths (Milton Keynes Council 2015). Milton Keynes' population in 2011 was 229,941 , covering an area of $89 \mathrm{~km}^{2}$ (8900 ha) with a population density of 2584 inhabitants per $\mathrm{km}^{2}$ (Office for National Statistics 2013).

Bedford $\left(52^{\circ} 80 \mathrm{~N}, 0^{\circ} 270 \mathrm{~W}\right)$ developed in the Middle Ages as a market centre and differs to Milton Keynes by possessing both a much longer history and a road network radiating outwards from its centre like many British towns. Its 2011 population was 106,940 and the town covers $36 \mathrm{~km}^{2}$ (3600 ha), with a population density of 2971 inhabitants per $\mathrm{km}^{2}$ (Office for National Statistics 2013).

Luton $\left(51^{\circ} 520 \mathrm{~N}, 0^{\circ} 250 \mathrm{~W}\right)$ developed heavily during the nineteenth century as an industrial centre. As such, its urban pattern contains large industrial parks and residential 'terrace' housing. Here considered as the combined Luton/Dunstable urban area, the region had a 2011 population of 258,018 and covers 58 $\mathrm{km}^{2}$ (5800 ha), with a population density of 4448 inhabitants per $\mathrm{km}^{2}$ (Office for National Statistics 2013).

The fine scale $(2 \mathrm{~m})$ resolution land use/land cover (LULC) map used in this study was created from
Fig. 1 Study area showing locations and land use/land cover classification of Bedford, Luton, and Milton Keynes, UK

colour infrared aerial photography originally at $0.5 \mathrm{~m}$ resolution obtained from LandMap Spatial Discovery (http://landmap.mimas.ac.uk/). The imagery was taken on 2 June 2009 for Bedford, 30 June 2009 and 24 April 2010 for Luton, and 8 and 15 June 2007 and 2 June 2009 for Milton Keynes, based on cloud-free image availability. Buildings and water features were identified from UK Ordnance Survey MasterMap layers, and remaining paved surfaces were separated from vegetation through the use of a Normalised Difference Vegetation Index (NDVI) threshold. An NDVI value threshold of 0.2 was used to distinguish vegetation $(\mathrm{NDVI} \geq 0.2)$ from non-vegetation (NDVI < 0.2). Subsequently, airborne LiDAR (Grafius et al. 2016) was used to categorize vegetation into height classes for short grass $(<0.5 \mathrm{~m})$, tall grass and shrubs $(0.5-2 \mathrm{~m})$, short trees $(2-10 \mathrm{~m})$, medium trees $(10-15 \mathrm{~m})$, and tall trees $(>15 \mathrm{~m})$ (Grafius et al. 2017, 2019). The land cover map was resampled to $2 \mathrm{~m}$ resolution for all modelling and analysis. GIS analysis, processing and modelling were conducted in ArcGIS 10.6 (ESRI 2017). A $2 \mathrm{~m}$ resolution provides a more accurate representation of fine-scale spatial heterogeneity and of small green space cover scattered in the urban matrix. A coarser resolution may underestimate green space cover and the supply of ESs.

Methodological framework

In this study, a BBN modelling approach was used for predicting ES trade-offs and synergies and used it to test the relationships between urban habitat structural features (patch area, connectivity and bird species abundance) and ES trade-offs and synergies. The methodological framework for testing the relationships between habitat structural features and ecosystem service trade-offs and synergies involved three steps. In the first, a cumulative current map was generated for each town based on circuit theory models. In the second, patch area, habitat connectivity and empirical abundance data were calculated for each town and used as model predictors in step three. Point count observed bird abundance survey data, point observed bird species richness survey data, data point connectivity values and data point ES trade-off and 
a

Bedford

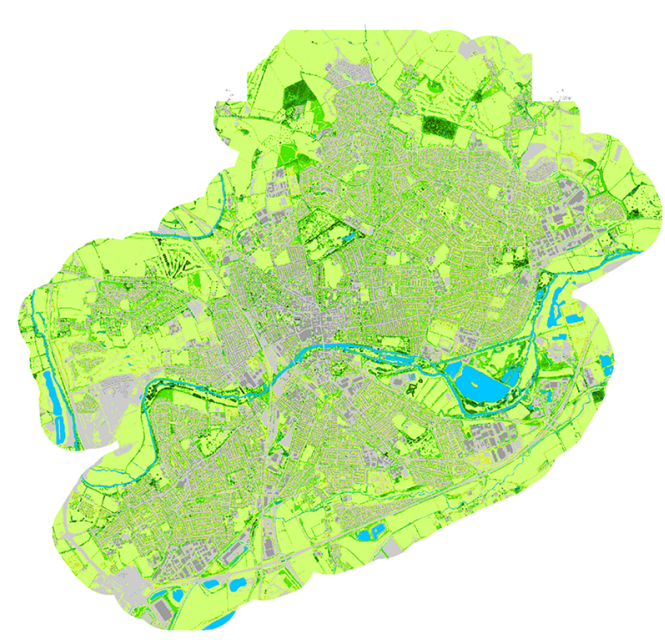

b

\section{Luton}

C

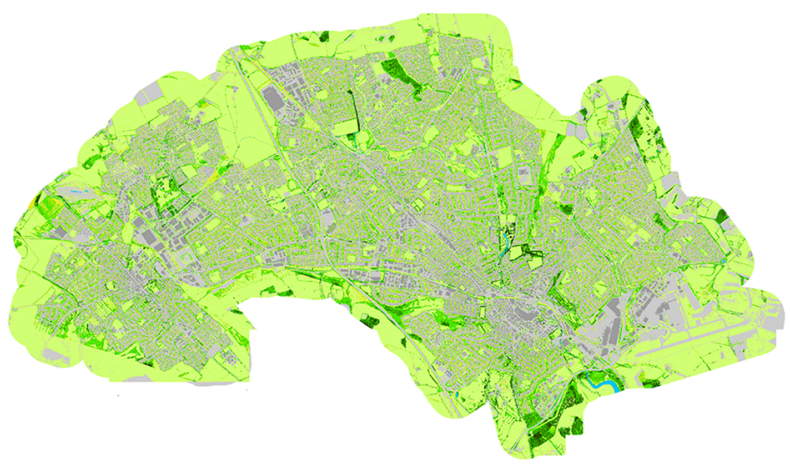

Milton Keynes
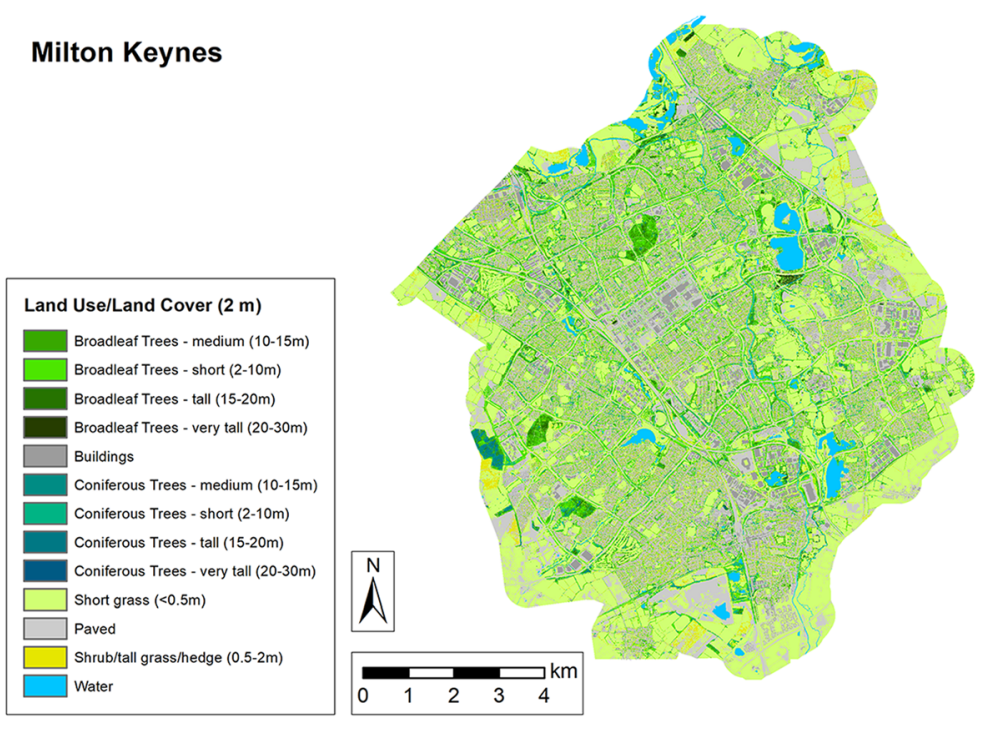

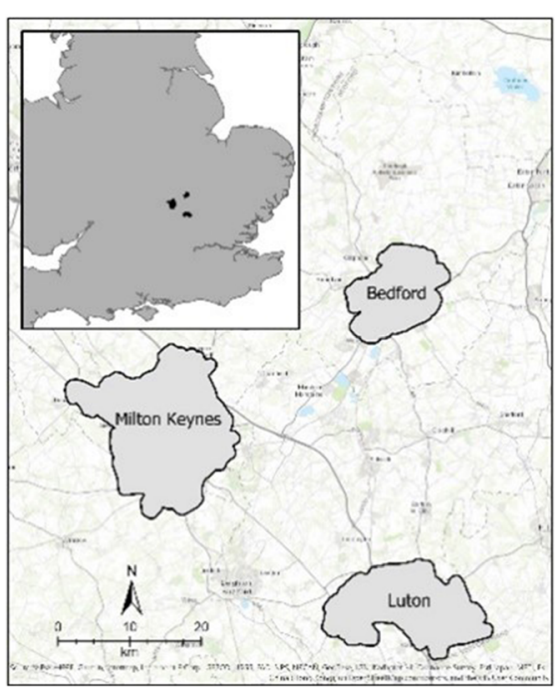


synergy values were associated with the patch area values and were combined across the three towns. The data point ecosystem service trade-off and synergy values were obtained from a principal component analysis conducted on six ecosystem services which represented Provisioning (water supply), Regulating (carbon storage, erosion control, nutrient retention, pollination) and Supporting (habitat quality) services (Karimi et al. 2021). The ESs were modelled with Integrated Valuation of Environmental Services and Trade-offs InVEST modelling suite version 3.4.4 (Sharp et al. 2016) using the LULC map described in the "Study area" section. The principal components' raster map values represented nutrient retention and carbon storage trade-offs (PC 1), habitat quality and pollinator abundance trade-offs (PC 2) and potential soil erosion and water supply synergies (PC 3 ) and were each used as response variable. In the third, BBN modelling and a sensitivity analysis were conducted (Fig. 2). The sensitivity of the model output to the predictors was assessed in order to explore the influence of those drivers in determining predicted ecosystem service trade-offs and synergies.

Connectivity and circuit theory

Connectivity metrics have been developed to measure landscape connectivity based on graph theory and network analysis (Saura and Torné 2009). Connectivity can be measured with network analysis. To depict habitats and corridors as networks, graph theory considers nodes as suitable habitat and links between nodes as the dispersal ability of a species. However, graph theory approaches are limited in their ability to consider spatial patterns of the landscape between habitat nodes. Least-cost path analysis applied in leastcost models provides a valuable method for conservation planning and corridor design. Least-cost paths calculates the shortest cumulative cost-weighted distance between a source and destination across a surface representing landscape resistance to movement (McClure et al. 2016).

A relatively recent approach for modelling functional connectivity has been to use circuit-theory connectivity models. In the circuit model, landscapes are represented as conductive surfaces, and low resistances are assigned to land cover types best facilitating species flow, and high resistances for land cover types impeding species movement (McRae et al. 2008). Using an electrical analogy, effective resistances, current flow and voltages calculated across the landscape are related to ecological processes, such as movement of species and gene flow.

In physics, Ohm's law states that the current through a conductor between two points is proportional to the voltage between the two points.

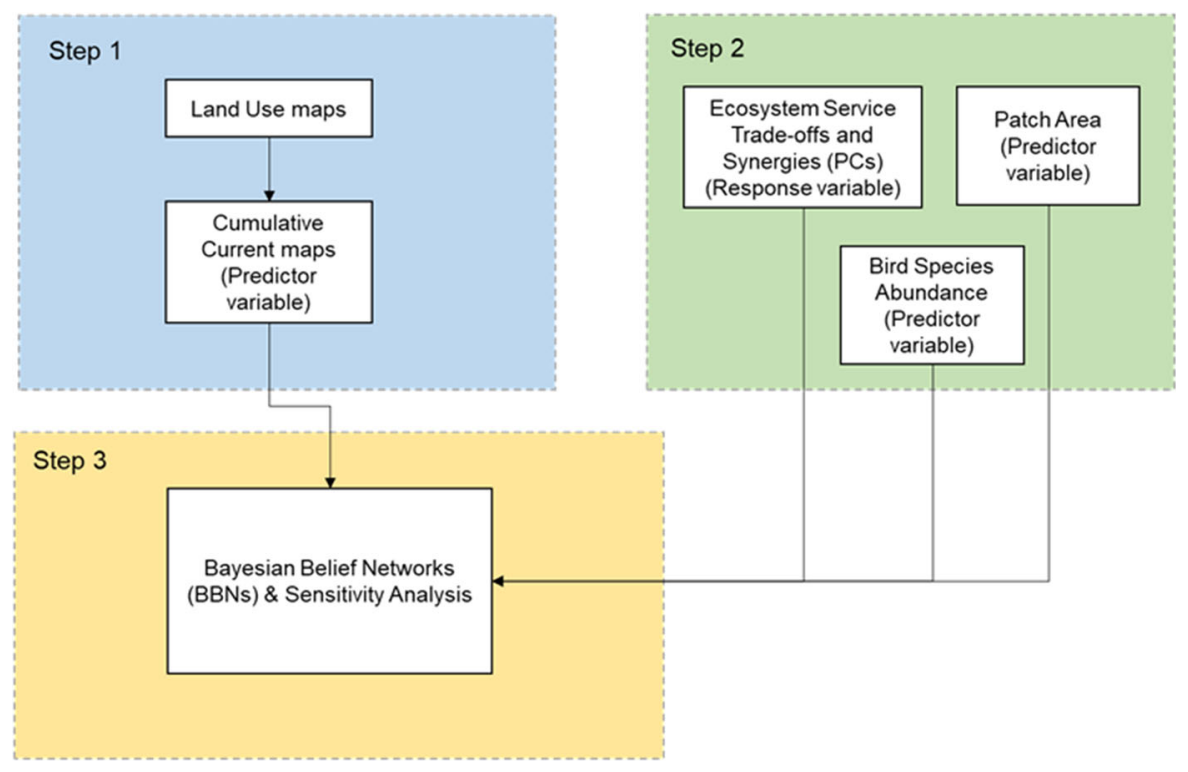

Fig. 2 Methodological framework 


$$
I=\frac{V}{R_{e f f}}
$$

where $I$ is the current through the conductor, $V$ is the voltage measured across the conductor and $R_{\text {eff }}$ is the effective resistance of the conductor. The total amount of current that flows across the circuit depends on the voltage applied and the configuration of the circuit.

To represent landscapes as circuits, a resistance map is used to represent willingness by species to traverse the landscape and core habitat nodes the source and destination of species flow. Kirchoff's circuit laws are then used to calculate current and voltage. The circuit model calculates the current between pairs of user-defined nodes (areas with zero resistance). When each pairwise result is summed, a cumulative current map is produced. Corridors with high current values and narrow widths can be identified which represent areas important for connectivity.

In the context of ecosystem services, circuit theory has been used to examine the landscape genetic structure and movements of pollinators, especially bees, in response to habitat and land-use changes (Dickson et al. 2019). Circuit theory is suitable for characterizing relative frequency of routine movements along multiple potential paths through urban and other fragmented landscapes and the method is considered to reflect ecological reality more accurately (McRae et al. 2008). In circuit theory, circuits are defined as networks of nodes connected by resistors (electrical components that conduct current) and are used to represent and analyse graphs (McRae et al. 2008). Circuit theory has been used to model landscape connectivity (Hanks and Hooten 2013).

Current models use Euclidean distance, least-cost path analysis, connectivity indices, least-cost distance and landscape resistance using circuit theory to model connectivity (McRae and Beier 2007; Saura and Pascual-Hortal 2007; McRae et al. 2008; McGarigal et al. 2012). A review revealed that an understanding of ecological connectivity within urban areas appears limited (LaPoint et al. 2015). Least-cost path models, connectivity analysis and circuit theory can be combined to identify and develop ecological corridors. The combined models enable priority corridors and 'pinch points' to be identified.
Landscape resistance and core area parameterisation

Habitat suitability and resistance maps were conceptualised to model the connectedness of the urban environment for the various types and distances of dispersal that can be expected of great tits (Parus major) and blue tits (Cyanistes caeruleus) and treating the species as indicators of the urban landscape's ability to facilitate wildlife movement. The resistance values were assigned to mapped pixels based on LULC class and, subsequently, modified by additional relevant factors and features. Highly suitable woodland patches within the study area were assigned a low resistance value of 1 if they were larger than 5 ha in size and 2 if they were smaller than this but consisted of tall trees $(>15 \mathrm{~m})$, as these represent relatively ideal habitats, being old and structurally complex and less impacted by edge effects. Woodlands and shrublands outside of core habitat patches were assigned slightly higher resistance values (respectively 5 and 10) to model their use as favourable to connectivity. Low grassland was parameterised not to count as favourable habitat and assigned a resistance value of 25. Paved land was parameterised as less suitable and assigned a resistance value of 30 , and water was selected as more extremely unsuitable and assigned a resistance value of 45 . Buildings were the least suitable and assigned a resistance value of 50 given their lack of habitat amenities and their presence as physical barriers to movement. Modifiers to the above base values were then applied. Land cover pixels greater than $45 \mathrm{~m}$ from woodland had 50 added to their initial resistance value due to the reluctance of woodland species to cross gaps wider than this (implemented as a modifying effect, so land cover still plays a role; for example, a wide gap over water will have a resistance value of $45+50=95$ ). The land cover types and modifiers were assigned resistance values according to Grafius et al. (2017). The resistance values ranged between 1 and 100. Higher values were related to built-up areas. Selection of core habitat nodes was based on predicted habitat suitability patch size, contiguity and structure. All woodlands greater than 10 ha were initially included, after which some were excluded on the basis of irregular shape, one core habitat node for each town.

Circuitscape software 4.0 (McRae et al. 2013) was used to calculate landscape connectivity and generate 
a cumulative current density map. The landscape resistance and core habitat node areas had to be converted to an ASCII format using 'Export to Circuitscape' extension for ArcGIS for use in the software. The short-circuit regions file was used to represent the same areas as the core habitat nodes. Short-circuit regions represent areas with zero resistance that the species under study can traverse freely with no cost. Circuitscape requires three input datasets: (i) input resistance data (ii) focal node location files and (iii) short-circuit regions file. Circuit models were generated using the pairwise mode in order to model connectivity between all pairs of 'focal nodes' (i.e. core habitat patches). A cumulative current density map was produced that combined the results of all pairwise current density maps. The cumulative current map was used as model predictor.

Since the values of the cumulative current maps are influenced by the number of node pairs, and each town contained a different number of core habitats (Bedford 7; Luton 14; Milton Keynes 11), the maps exhibited different data ranges and were rescaled to values between zero and one to facilitate comparison between maps.

Input data: patch area, connectivity and empirical abundance data

Point count survey data was used to estimate bird abundance and bird species richness (Plummer and Siriwardena 2018). The survey data was collected positioning observation points $(n=454)$ within 116 tiles (grid squares of $500 \mathrm{~m} \times 500 \mathrm{~m}$ ) which had been randomly selected for bird surveying using a stratified sampling design. Abundance estimates were calculated at each observation point by summing up the maximum counts of singing and non-singing $P$. major and C. caeruleus individuals within a radius of $200 \mathrm{~m}$. The maximum value across all points within each tile was taken as indicator of that year's abundance (2013). This produced an estimate of overall abundance at that survey point. Bird species richness was calculated at each observation point by summing up the total of bird species recorded within a radius of $200 \mathrm{~m}$ (Grafius et al. 2019). Overall bird species richness values for modelling input were based on the maximum observed richness across all points within a tile and taken as indicators of that year's richness (2013). This produced an estimate of overall richness at each point.
Patch area and connectivity data were based on a raster LULC map. Patch area (ha) was calculated using Fragstats software (McGarigal et al. 2012). Corridor-based metrics of habitat connectivity have been identified as strong predictors of biodiversity in urban areas (Beninde et al. 2015). Cumulative current maps were produced following Grafius et al. (2017) who used data on great tits (P. major) and blue tits ( $C$. caeruleus) movements to model functional connectivity. These woodland species have adapted to life in UK suburban environments, but their movements within urban environments are constrained by habitat fragmentation (Cox et al. 2016) making them suitable species for corridor-based metrics of habitat connectivity. They have similar habitat preference, habit and behaviour and their suitable habitats are represented by large woodlands (Grafius et al. 2017).

Ecosystem service trade-offs and synergies input data

The data outputs of a principal component analysis conducted on six ES spatial datasets were used for GIS processing and subsequently as response variable for BBN modelling. The ESs analysed represented Provisioning (water supply) Regulating (carbon storage, erosion control, nutrient retention, and pollination) and Supporting (habitat quality) services (Karimi et al. 2021). The three principal components represented nutrient retention and carbon storage trade-offs (PC 1), habitat quality and pollinator abundance trade-offs (PC 2) and potential soil erosion and water supply synergies (PC 3).

For each town, a dataset where each observation represented a point observation of counts of bird abundance (within a radius of $200 \mathrm{~m}$ ), a point observation of bird species richness (within a radius of $200 \mathrm{~m}$ ), data point cumulative current raster map values, data point principal components raster map values and patch area values found at the same location was data processed using the Extract MultiValues to Points tool in ArcGIS Desktop 10.6. The datasets of each town were combined using JMP software (SAS Institute Inc. 2018) to generate a dataset of 116 'cases' (observations) and used for Bayesian modelling. 
Bayesian Belief Networks

Bayesian Belief Networks (BBNs) are multivariate statistical models, acknowledged for their unique probabilistic modelling approach and their high model transparency (Landuyt et al. 2013). Bayesian belief techniques have several model related advantages, e.g. the possibility of taking into account uncertainties and combine expert knowledge with empirical data (Van der Biest et al. 2014). As networks, they can cope effectively with incomplete information on the relationships between variables. BBNs are well-suited to complexity and incomplete knowledge, which are common in ecological systems (Landuyt et al. 2013). BBNs are useful tools for modelling ecological predictions and used for assessing the influence of environmental predictor variables on ecological response variables (Marcot et al. 2006).

\section{Model construction}

BBN modelling was conducted using Netica software (Norsys Software Corp. 2018). The BBN made predictions within vegetated areas. Bird surveys were centred on vegetated areas, but encompassed mixed areas containing both vegetated and non-vegetated areas. Separate but comparable (i.e. possessing the same network structure) BBN models were created for each of the three principal components (representing trade-offs and synergies among services) with each ES trade-off or synergy as the model outcome. Each BBN model included patch area, connectivity and bird species abundance as model predictors, and ES tradeoff (or synergy) as the response variable. A separate influence network was created with bird species richness as predictor variable in place of bird abundance preserving the other variables in the model. The predictor variables were chosen for their theorised influence on ES trade-offs and synergies. Conditional probabilities define the relationships between the habitat structural features and the ES trade-offs, and were obtained by processing individual 'cases', where each case represented an ES trade-off (or synergy) value and habitat structural feature values found at the same location. The model then used these conditional probabilities to predict ES trade-offs (or synergies) at every vegetated location (116 points). All nodes were automatically discretised with ten states each. A simplification of this with five states for each input parameter and three for dependent variables was used for ease of visualisation of model structure (Fig. 3).

Model performance was assessed using a goodnessof-fit measure, reported as the model's error rate, that expresses the frequency with which the model's strongest predictions is incorrect against the observed data. It supplies an analogous measure of confidence in the model predictions (Aalders 2008). A sensitivity analysis was conducted on the BBN models. Sensitivity analysis determined how much the beliefs (i.e. ES trade-off and synergy predictions) were influenced by each new finding in the predictor nodes (i.e. changes in patch area, connectivity and bird species abundance). Sensitivity was expressed as the expected reduction in variance of the expected real value due to a finding in a particular node (e.g. complete insensitivity would occur if the addition of new data records to the model caused no reduction in the variance). The conditional probabilities for the node states were extracted from the models and graphed as a heat map to show the predicted factor probability at each state level of trade-off (or synergy).

\section{Results}

The cumulative current maps

The modelling of landscape connectivity for $P$. major and $C$. caeruleus resulted in a cumulative current map for each town (Fig. 4). The intensity of the current was used as a proxy for wildlife movement and was calculated between each pair of core habitats. For Bedford, the cumulative current was affected by the distribution of core habitat areas with the southwestern region exhibiting a decrease in modelled flow values due to the presence of only one major habitat patch in that region. The proximity of habitat nodes to one another in other areas of the town appeared to generate an increase in current values. For Luton, modelled current flows were greater in the southeastern region due to the proximity of the habitat nodes to one another. Modelled movement patterns appeared to be similar but had a greater emphasis on wooded corridors and mixed habitats, such as through residential gardens between rows of terraced housing and vegetated corridors along major transport arteries. In Milton Keynes, modelled current flows were higher along wooded corridors and vegetated road verges. 


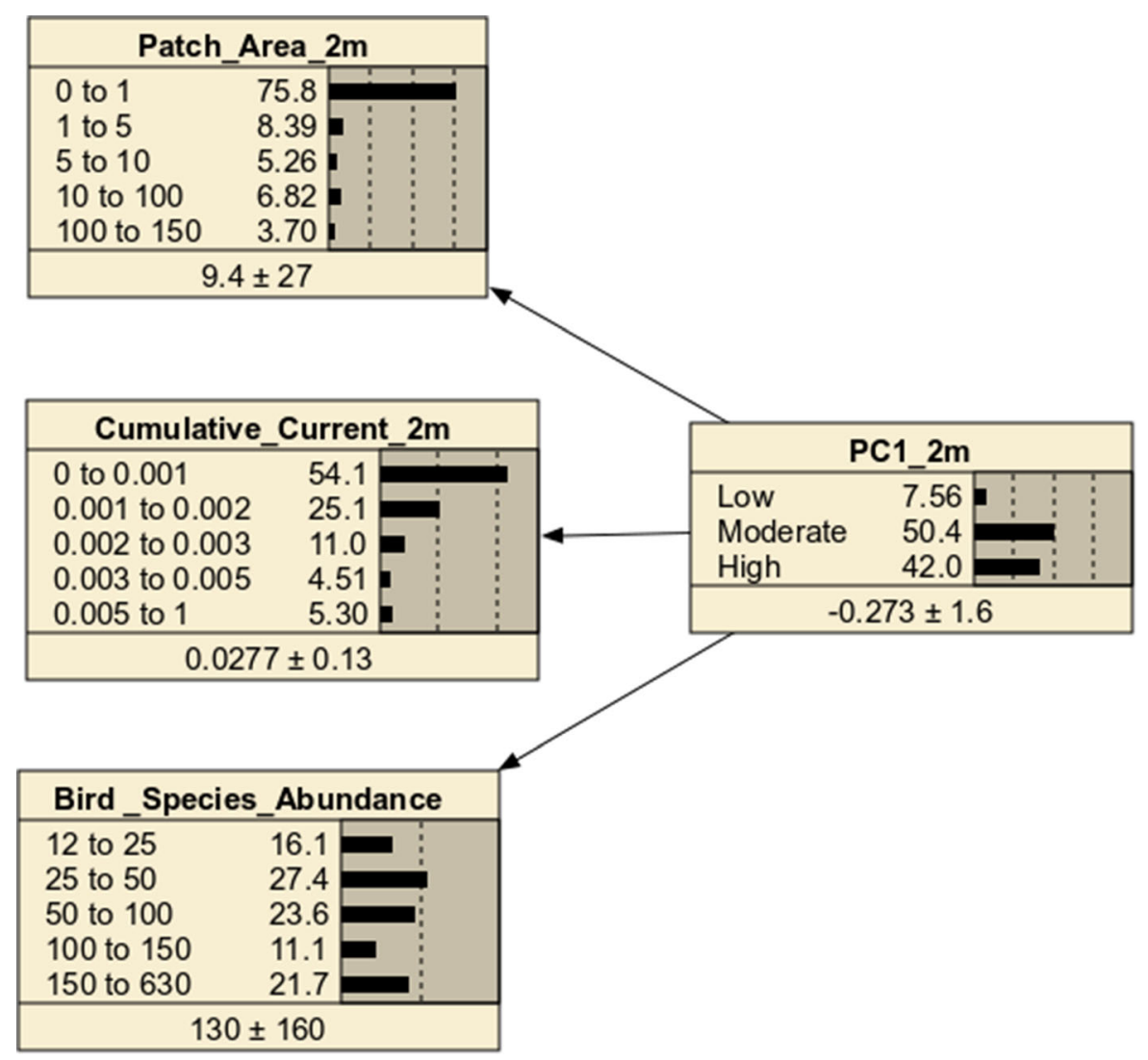

Fig. 3 Example of Bayesian Belief Network model structure for Nutrient retention and Carbon storage trade-offs. All models used a comparable structure, with the dependent variable and the conditional probabilities changing between models. The influence diagram illustrates the relationships between the dependent

Current flows appeared to follow the major vegetated grid road network and were higher on the western side of the region where the core habitat nodes were distributed. Modelled current flows along wooded corridors in residential districts also suggest the importance of these features. Conversely, modelled current flows in the city centre and industrial estates had a sparser flow network.

The circuit model of flow through a network is relevant to nutrient retention, carbon storage, habitat quality, pollination, erosion control and water supply services as the supply of the services are each associated with either a specific land cover type provider (e.g. carbon storage for woodland) or multiple land cover types providers (e.g. pollination for grassland and woodland). The provision of ESs changes as a result of changes in land use patterns or changes in the composition and structure of different variable (i.e. ES trade-offs or synergies) and the independent variables. Arrows denote the direction of probabilistic influence implemented in software rather than causal relationships between the factors

ecosystems. An extensive modification to blue-green infrastructure and land cover affects the supply of ecosystem services. The cumulative current maps showed that the network structure and how the core habitat areas are distributed influence landscape connectivity. The circuit model of flow through the network can influence the provision of ESs and is influenced by the surrounding built-up matrix. Woodland areas (i.e. suitable habitat for bird flow) provide carbon storage, nutrient retention, habitat quality, erosion control, pollination and water supply (surface runoff reduction and baseflow) services.

In the initial cumulative current maps, Bedford contained lower overall modelled current values (maximum 4.99, mean 0.03) than Milton Keynes (maximum of 8.38, mean 0.04) and Luton (maximum 21.63, mean 0.24) due to a lower number of core habitat nodes. After rescaling, Luton had the highest 
(a)

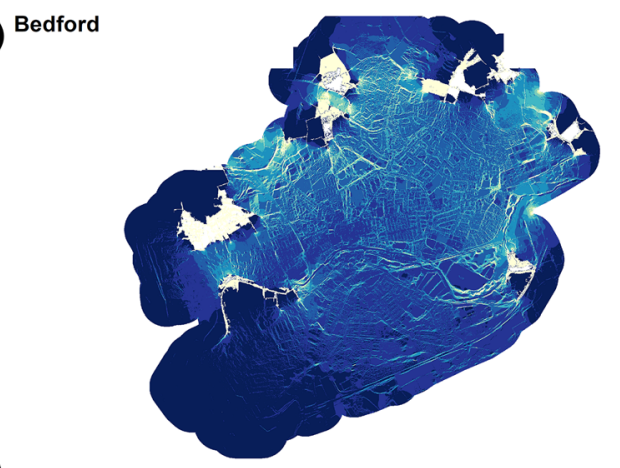

(b)

Luton

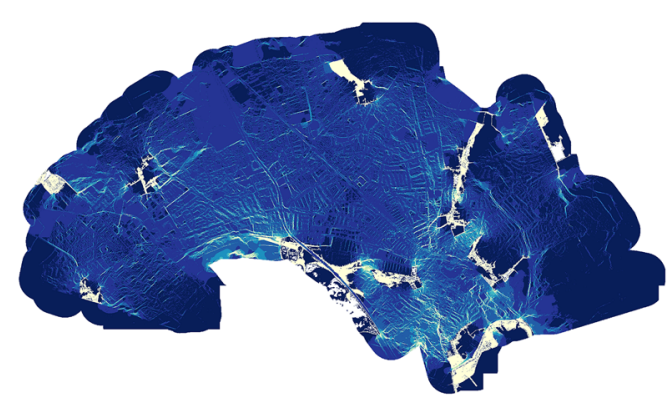

(c)

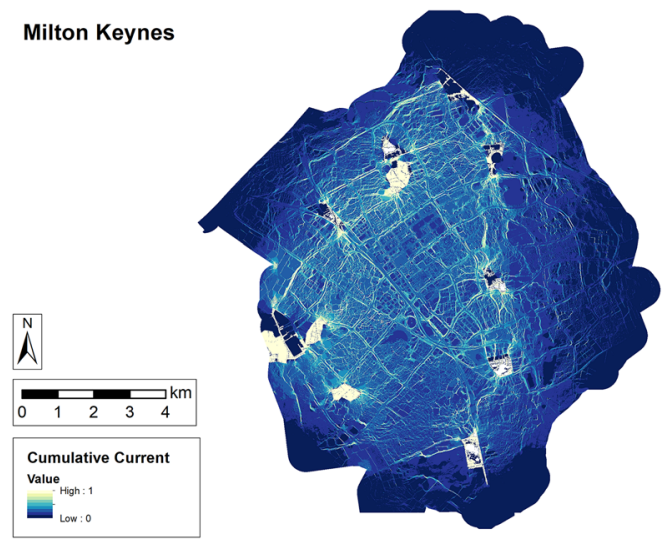

Fig. 4 Modelled cumulative current maps (rescaled to facilitate comparison between towns) at a $2 \mathrm{~m}$ spatial resolution for Bedford, Luton and Milton Keynes, UK

mean connectivity but also the highest variability (mean 0.0111, SD 0.0873). Milton Keynes (mean 0.0046, SD 0.0555) and Bedford (mean 0.0059, SD 0.0598 ) had lower values.
Model performance and predictor sensitivity

Error rates for the models ranged between $41 \%$ for the PC describing Habitat quality and Pollinator abundance trade-offs and $45 \%$ for the PC describing Nutrient retention and Carbon storage trade-offs (Table 1). The model error rates for the influence network with bird species richness ranged between $41 \%$ for the PC describing nutrient retention and carbon storage trade-offs and $48 \%$ for the PC describing habitat quality and pollinator abundance trade-offs (see supplementary materials, Table A1).

Parameter sensitivities in the models reflect the strength of the relationships between predictors and ES trade-off and synergy predictions. Connectivity exhibited the greatest sensitivity for two of three ES trade-offs and synergies. Predicted trade-offs of nutrient retention and carbon storage and habitat quality and pollinator abundance were most sensitive to connectivity and exhibited relatively high percentage of variance reduction (respectively, 7.3 and 3.6). Habitat quality and pollinator abundance trade-off predictions were least sensitive to bird abundance (1.0). Potential soil erosion, water supply synergies predictions were most sensitive to bird abundance (3.0). Potential soil erosion, water supply synergies predictions were most sensitive to bird species richness (2.6).

Probabilistic associations between landscape factors and ES trade-offs and synergies

Heat maps show the probabilistic associations between the values of predictor variables and the predicted ES trade-offs or synergies levels (Fig. 5; Table 2). High conditional probabilities reflect the likelihood of an outcome given a set of parent node states. For example, low and moderate nutrient retention and carbon storage trade-offs are expected in areas with low patch area, whereas high nutrient retention and carbon storage trade-offs are expected in areas with low patch area and low connectivity. Patch area and connectivity appeared to be strong predictors of ES trade-offs and synergies. Predicted habitat quality and pollinator abundance trade-offs exhibited strong associations with patch area and connectivity, with the highest conditional probabilities associated with low patch area and low connectivity at moderate and high levels of habitat quality and pollinator 
Table 1 Results of case testing (error rate) and sensitivity analysis (percent in variance reduction as a metric of the relative importance of each input variable) on Bayesian Belief Network models for Nutrient retention and Carbon storage
Trade-offs (PC1), Habitat quality and Pollinator abundance Trade-offs (PC2) and Soil erosion and Water supply Synergies (PC 3) at $2 \mathrm{~m}$ resolution

\begin{tabular}{lllll}
\hline & Error rate $(\%)$ & \multicolumn{3}{l}{ Sensitivity (Percent in variance reduction) } \\
\cline { 3 - 5 } & & Connectivity & Bird Sp. abundance & Patch area \\
\hline PC1 & 44.83 & 7.34 & 4.99 & 4.42 \\
PC2 & 40.52 & 3.63 & 1.00 & 3.07 \\
PC3 & 43.10 & 2.01 & 3.05 & 1.74 \\
\hline
\end{tabular}

(a) Nutrient Retention and Carbon Storage Trade-offs
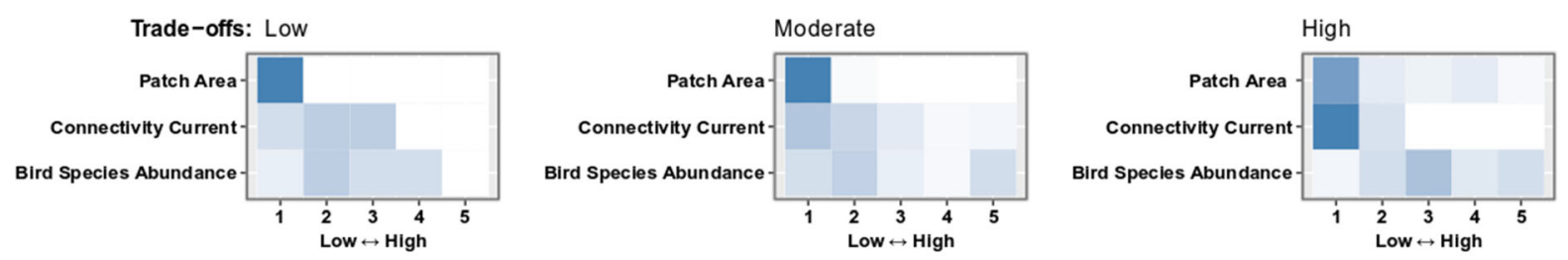

(b) Habitat Quality and Pollinator Abundance Trade-offs
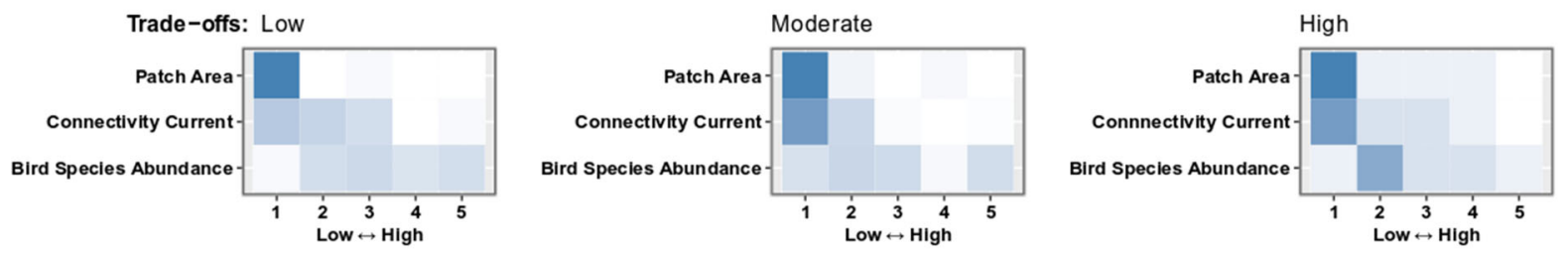

\section{(c) Potential Soil Erosion and Water Supply Synergies}

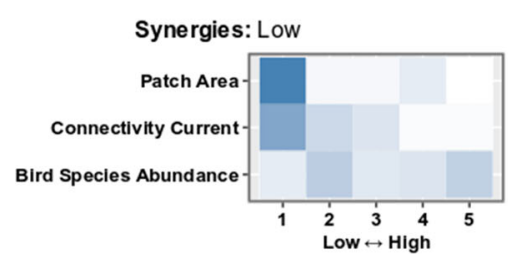

Fig. 5 The heat maps show the conditional probabilities driving each model. These represent the strength of the relationships between the input parameters (patch area, connectivity and bird species abundance; values of bin ranges are shown in Table 2) and the predicted trade-offs (or synergies). Darker cells denote

abundance trade-offs. Low levels of predicted potential soil erosion and water supply synergies appeared to be associated with low patch area. High levels of potential soil erosion and water supply synergies predictions were associated with low patch area and moderately low connectivity. Predicted ES trade-offs and synergies exhibited weak associations with bird species abundance. Conversely, predicted ES tradeoffs and synergies exhibited strong associations with bird species richness (see Supplementary Materials). 
Table 2 Bin ranges for input parameter values in Fig. 4 heat maps of Bayesian model conditional probabilities

\begin{tabular}{llllll}
\hline Bins & Low & Moderately low & Moderate & Moderately high & High \\
\hline Patch area (ha) & $0-1$ & $1-5$ & $5-10$ & $10-100$ & $100-150$ \\
Connectivity current & $0-0.001$ & $0.001-0.002$ & $0.002-0.003$ & $0.003-0.005$ & $0.005-1$ \\
Bird Sp. abundance & $12-25$ & $25-50$ & $50-100$ & $100-150$ & $150-630$ \\
\hline
\end{tabular}

\section{Discussion}

The modelling approach described represents a method for assessing the factors that influence ES trade-offs and synergies and was used to test whether connectivity drives ES trade-offs and synergies. Our study showed that connectivity influences ES tradeoffs and synergies and the supply of ESs and that the modelling framework can be used to test the factors that influence ES trade-offs and synergies in complex landscapes.

Predicted ES trade-offs and synergies and key drivers of ES trade-offs and synergies

The model error rates did not vary widely (Table 1 ), the mean rate among all models (43.0\%) was comparable to results found in other studies applying BBNs to environmental systems (Aalders 2008; Grafius et al. 2019). The finding of comparable error rates supports the assertion that the predictors habitat connectivity and patch area we consider here are strong determinants of ecosystem service trade-offs in urban areas.

The conditional probability heat maps show the relationships between the ES trade-offs and synergies and habitat structure (Fig. 5). Connectivity emerged as an important factor for multiple ES trade-offs and synergies, with low connectivity associated with high trade-offs between nutrient retention and carbon storage and between habitat quality and pollinator abundance. There is therefore an expectation that in areas dominated by low connectivity the trade-offs between these ecosystem services will be high. Importantly, low patch area was associated with ES trade-off and synergy predictions. Large patches of vegetation are more likely to possess a greater variety of habitats and heterogeneity than smaller patches, with a higher supply of ESs and biodiversity (Leitão et al. 2006). Conditional probabilities (Fig. 5) further support the expectation that nutrient retention and carbon storage trade-offs, habitat quality and pollinator abundance trade-offs and potential soil erosion, water supply synergies will be greater in patches with low patch area and with low to moderately low connectivity. This is consistent with past research that a decrease in patch area and connectivity reduces the supply of ESs (Mitchell et al. 2013; Cordingley et al. 2015; Eigenbrod 2016). Landscape connectivity change is assumed to have contrasting effects on ESs. Studies suggest that decreased connectivity will reduce ES provision. The findings of this study show that in areas with low to moderately low connectivity trade-offs and synergies will be high for the considered ESs. Low to moderately low connectivity is expected in areas to support high trade-offs between services and thus decrease the provision of ESs.

Patch area and connectivity have been found to be important for enhanced bird species abundance (Shanahan et al. 2011; Kang et al. 2015). Connectivity has been found to have an important influence on bird species richness as it increases the number of patches from which species can arrive (Chisholm et al. 2011; Shanahan et al. 2011). High levels of potential soil erosion and water supply synergies predictions appeared to be associated with low patch area, moderately low connectivity and moderate bird species abundance, suggesting that in areas with low patch area, moderately low connectivity and moderate bird species abundance soil erosion and water supply synergies will be high. The conditional probabilities for bird species richness were more marked compared to bird species abundance suggesting a stronger relationship with ES trade-offs and synergies (see Supplementary Materials).

Conditional probabilities show that low to moderately low connectivity is an important driver of tradeoff and synergy predictions for nutrient retention and carbon storage, habitat quality and pollinator abundance and for potential soil erosion and water supply. The probabilistic associations between predicted ES 
trade-offs and synergies and landscape structural factors, patch area and connectivity, may be consistent with the fact that low patch area and low connectivity affect trade-offs and synergies between ecosystem services (Mitchell et al. 2013, 2015b). Predicted nutrient retention and carbon storage trade-offs were most sensitive to connectivity. This suggests that connectivity may be a key driver of nutrient retention and carbon storage trade-offs. The mechanisms by which nutrient retention and carbon storage trade-offs are created may be driven by functional connectivity (Bennett et al. 2009). Nutrient retention and carbon storage trade-offs may be driven by connectivity as a result of extensive modification to land cover and arrangement of land cover types in urban areas. Low levels of nutrient retention and carbon storage tradeoffs were associated with woodlands whereas high levels of nutrient and carbon storage trade-offs with grasslands. High levels of predicted nutrient retention and carbon storage trade-offs were associated with low connectivity. Conditional probabilities support the expectation that nutrient retention and carbon storage trade-offs will be greater in patches with low connectivity, suggesting that low connectivity supports high nutrient retention and carbon storage trade-offs. An increase in connectivity through the extensive modification of land cover would correspond to an increase in woodland vegetation cover (i.e. suitable habitat for bird flow), and subsequently lower nutrient retention and carbon storage trade-offs. This would result in an increase in carbon storage and a higher supply of ESs.

Predicted habitat quality and pollinator abundance trade-offs were most sensitive to connectivity. This suggests that connectivity may be a key driver of habitat quality and pollinator abundance trade-offs. Connectivity depends on the physical and functional connection between patches and the arrangement of land cover types. Habitat quality depends on the habitat's proximity to human land uses and the intensity of these land uses. In urban areas, it has been found that pollinator abundance was prevalent due to the presence of a variety of habitats for nesting and foraging for pollinators (Baldock et al. 2019). The mechanisms by which habitat quality and pollinator abundance trade-offs are created may be driven by patch area and connectivity which affect the supply of habitat quality and pollinator abundance services. The spatial arrangement and connectedness of land cover types influences the provision of ESs which will have either positive or negative effects on service flow depending on the service in question. Human activities that alter landscape connectivity such as habitat fragmentation can affect habitat quality and pollinator abundance. Along a suburban-urban gradient, habitat quality would be reduced whereas pollinator abundance enhanced. Habitat quality is enhanced by natural and semi-natural land cover, whereas pollinator abundance is enhanced by the availability of a variety of habitats. Habitat quality and pollinator abundance trade-offs may be driven by patch area and connectivity and by the influence of the surrounding built-up areas. High levels of predicted habitat quality and pollinator abundance trade-offs were associated with low connectivity. Conditional probabilities support the expectation that habitat quality and pollinator abundance trade-offs will be greater in areas with low connectivity and low patch area. Habitat quality and pollinator abundance trade-offs were higher on suburban grasslands. Low connectivity which represented unsuitable habitat for bird flow was associated with grasslands. An increase in connectivity through the extensive modification of land cover would correspond to an increase in woodlands (i.e. suitable habitat for bird flow). This would correspond to an increase in habitats for pollinators, and as a result lower habitat quality and pollinator abundance trade-offs. This would result in an increase of habitat quality and pollinator abundance, and subsequently a higher supply of ESs. The habitat quality and pollinator abundance trade-offs appeared to be driven by connectivity, land use patterns and ecological processes.

Predicted potential soil erosion and water supply synergies were most sensitive to bird abundance. Bird species abundance and species richness were each included in the model as an indicator of biodiversity than as drivers of ES trade-offs and synergies to test whether there is concordance with the provision of ESs (i.e. biodiversity is increasingly important as the number of services considered increases). Conditional probabilities support the expectation that soil erosion and water supply synergies will be greater in patches with moderately low connectivity, low patch area and moderate bird abundance. High levels of potential soil erosion and water supply synergies predictions were associated with moderately low connectivity (i.e. suitable habitat for bird flow) and moderate bird abundance. A possible explanation is that patch area in 
combination with connectivity increases bird abundance (Shanahan et al. 2011; Kang et al. 2015). An increase in patch area and connectivity through the extensive modification of land cover would correspond to an increase in woodland areas (i.e. suitable habitat for bird flow), and subsequently an increase in bird abundance. An increase in woodland vegetation increases carbon storage, habitat quality, erosion control, pollination and water supply services and the supply of ESs.

Potential soil erosion, water supply synergies were sensitive to patch area and connectivity. High levels of predicted potential soil erosion and water supply synergies appeared to be associated with moderately low connectivity and low patch area. There is therefore an expectation that in patches with low patch area and moderately low connectivity the soil erosion and water supply synergies will be high and would result in vegetation-field edge effects (Mitchell et al. 2015b). Erosion regulation is dependent on the flow of water and vegetation cover and a decrease in habitat connectivity (i.e. vegetation cover) as described here would result in an increase in surface runoff and soil erosion. The mechanisms by which soil erosion and water supply synergies are created may be driven by connectivity and by an interaction between services (Bennett et al. 2009). Impervious land increases surface runoff and decreases water infiltration. Conditional probabilities support the expectation that soil erosion and water supply synergies will be greater in patches with low patch area and moderately low connectivity. High levels of soil erosion and water supply synergies were associated with urban grassland and urban trees and woodland areas. An increase in connectivity through the extensive modification of land cover would correspond to an increase of woodland areas (i.e. suitable habitat for bird flow). This would correspond to a decrease in soil erosion and water supply synergies as woodland areas mitigate surface runoff and protect from soil erosion. Large patches of vegetation protect larger areas from soil erosion and allows the recharge of the water table (Leitão et al. 2006). This would result in an increase in erosion control and a decrease in surface runoff, and thus a higher supply of ESs. Potential soil erosion, water supply synergies may be driven by landscape structure, connectivity, topography and ecological processes. The combined effect of low patch area and moderately low connectivity may create potential soil erosion and water supply synergies.

Implications, further research and BBN modelling

The findings show that connectivity influences ES trade-offs and synergies with implications in the design of green space, ecological networks and sustainable ecosystem management. The cumulative current maps represented modelled current values of bird flow in urban areas based on habitat suitability (i.e. large woodlands) and land cover resistance. After rescaling, Luton exhibited a higher mean current value than Milton Keynes and Bedford. The higher mean values for Luton are an effect of a higher number of core habitats, its high tree cover and the positive influence of patterns and forms favourable to connectivity (e.g. its lower water cover). The findings show that extensive modification to land cover affects the circuit model of flow through the network and the supply of ESs. Green space structure and connectivity affect the supply of ESs creating trade-offs and synergies between services and form bundles of ESs. Each service responds differently to the variation of landscape structure even if the services do not interact strongly. Connectivity is important in the design of ecological networks in urban areas. A blue-green infrastructure and associated ESs can provide insurance by helping to buffer from disturbances such as flooding, heat stress, landslides and storms. Human activities which alter connectivity such as fragmentation and ES use can affect the provision of ESs. The structure of an ecological network and how the system components are connected is important. The identification of areas with multiple ESs as components of an ecological network and ES bundles could help in orienting management strategies to sustainability in urban areas. Large and better-connected habitat patches of tall and mature vegetation may confer resilience to a bundle of ESs.

The modelling approach and ES bundle analysis can be used to analyse green infrastructure and associated ESs. Analyses of synergies and trade-offs and identification of multifunctional key areas enable policymakers to maximize ESs. A blue-green infrastructure provides a number of benefits and services, but different green areas will have different ecological functions and provide different ecosystem services. To ensure the flow and access to ecosystem services is not 
interrupted, representative successional stages and different kinds of green areas in different urban contexts should be planned and managed for (Andersson 2006). As ESs interact and are affected by connectivity, which create trade-offs and synergies between services and form bundles, an understanding of the possible effects of connectivity on green space is vital to build a resilient supply of ESs (McPhearson et al. 2015) and enhance a multifunctional blue-green infrastructure so as to counteract climate change and land use. An understanding of the delivery of multiple ESs of an ecological network allows to identify the areas where managers can focus conservation planning objectives and develop sustainable development schemes.

Further studies on the effects of landscape structure on ES provision are needed to test and develop a better understanding of the effects of drivers on the provision of ESs. ESs are the co-products of socio-ecological systems and depend not only on ecosystem functions and ecological processes but also on social and biophysical variables (Eigenbrod 2016). Therefore, the amount and configuration of social variables such as land management systems, the distribution of wealth and human populations should be considered as possible drivers which affect the demand for ESs. Conceptual frameworks built on meta-ecosystem and ecological network theories are needed to develop a better understanding of the effects of connectivity on ESs (Thompson et al. 2017).

The findings of the conditional probability heat maps showed that for the considered ESs high levels of predicted trade-offs appeared to be associated with low patch area and low to moderately low connectivity. There is therefore an expectation that in areas with low patch area and low to moderately low connectivity, for the considered ESs, trade-offs between services will be high and thus result in a decrease in ES provision. This implies that large habitat patches and high landscape connectivity provide more synergies. Patch type (i.e. natural or semi-natural habitats) is also important as not all patches are (natural) habitats and habitat quality influences the supply of ESs and species. Our findings may be relevant in the design of increased connectivity through blue-green infrastructure.

An additional consideration is that the implications of connectivity for the resilience of ESs are complicated by the fact that socio-ecological processes operate simultaneously at different scales. Drivers may operate at local, regional and global scale. Connectivity may safeguard ecosystem services against a disturbance either by facilitating recovery or by constraining locally the spread of a disturbance (Dakos et al. 2015). At the same time, highly connected systems increase the potential for disturbances to spread. Changes to landscape connectivity and the provision of services can depend on the scale at which ESs are altered. An understanding of the possible effects of disturbances and hazards in urban areas on multiple ESs is vital in sustainable cities for building and ensuring a resilient supply of ESs.

The BBN modelling approach offers an advantage to other modelling methods as it combines the possibility to use empirical data and expert knowledge (Landuyt et al. 2013; Van der Biest et al. 2014). The general framework can be applied to other potential drivers that influence ES trade-offs and synergies. This may provide a better understanding of the effects of drivers on ES trade-offs and synergies, through complex interactions with different species and processes, and an understanding of the relationships among ESs and the mechanisms behind these relationships, whether the services are responding to a shared driver or interacting (Bennett et al. 2009).

\section{Conclusions}

The present study assessed the influence of connectivity on ES trade-offs and synergies at a fine $(2 \mathrm{~m})$ spatial resolution, at a landscape scale $\left(>100 \mathrm{~km}^{2}\right)$. We demonstrated that by applying a BBN modelling approach the influence of landscape and habitat structural features on ES trade-offs and synergies can be tested. Our models performed with error rates similar to BBN models used in other environmental contexts. The approach provides useful information on the sensitivity of ES trade-offs and synergies to different landscape structural features.

Our findings showed that patch area and connectivity exerted a strong influence on ES trade-offs and synergies and support the principle that, broadly, large and better-connected patches of vegetation increase ES provision and bird abundance in urban areas. Connectivity was found to be the most influential variable in determining two of three ES trade-offs and synergies. Low patch area and low to moderately low 
connectivity were associated with high levels of ES trade-offs and synergies predictions. In this study landscape connectivity affected multiple ESs and may form bundles.

Landscape management requires an understanding of how landscape connectivity affects ESs and their interactions. A BBN modelling approach may provide an effective solution to test the potential factors that drive ES trade-offs and assess how ES trade-offs respond to the variation of urban landscape structural features, and thereby relevant to landscape-scale research and ES management. BBNs are important tools for assisting in decision-making and scenario testing, and for urban planning. Further research is needed to understand how ecological networks enhance the resilience of urban ESs.

Acknowledgements This work was supported by the UK Natural Environment Research Council [Grant Number NE/ M009009/1]. The authors are grateful to the Natural Environment Research Council (NERC). This research (Grant Number NE/J015067/1) was conducted as part of the Fragments, Functions and Flows in Urban Ecosystem Services (F3UES) project as part of the larger Biodiversity and Ecosystem Service Sustainability (BESS) framework. BESS is a 6-year programme (2011-2017) funded by the UK Natural Environment Research Council (NERC) and the Biotechnology and Biological Sciences Research Council (BBSRC) as part of the UK's Living with Environmental Change (LWEC) programme. This work presents the outcomes of independent research funded by NERC and the BESS programme, and the views expressed are those of the authors and not necessarily those of the BESS Directorate or NERC.

Data availability The data that support the findings of this study are openly available in CORD at http://doi.org/10.17862/ cranfield.rd.14345618.

\section{Declarations}

Conflict of interest All authors declare that they have no conflict of interests.

Open Access This article is licensed under a Creative Commons Attribution 4.0 International License, which permits use, sharing, adaptation, distribution and reproduction in any medium or format, as long as you give appropriate credit to the original author(s) and the source, provide a link to the Creative Commons licence, and indicate if changes were made. The images or other third party material in this article are included in the article's Creative Commons licence, unless indicated otherwise in a credit line to the material. If material is not included in the article's Creative Commons licence and your intended use is not permitted by statutory regulation or exceeds the permitted use, you will need to obtain permission directly from the copyright holder. To view a copy of this licence, visit http://creativecommons.org/licenses/by/4.0/.

\section{References}

Aalders I (2008) Modeling land-use decision behavior with Bayesian belief networks. Ecol Soc 13:16

Andersson E (2006) Urban landscapes and sustainable cities. Ecol Soc 11:34

Baldock KCR, Goddard MA, Hicks DM, Kunin WE, Mitschunas N, Morse H, Osgarthorpe LM, Potts SG, Robertson KM, Scott AV, Staniczenko PPA, Stone GN, Vaughan IP, Memmott J (2019) A systems approach reveals urban pollinator hotspots and conservation opportunities. Nat Ecol Evol 3:363-373

Beninde J, Veith M, Hochkirch A (2015) Biodiversity in cities needs space: a meta-analysis of factors determining intraurban biodiversity variation. Ecol Lett 18:581-592

Bennett EM, Peterson GD, Gordon LJ (2009) Understanding relationships among multiple ecosystem services. Ecol Lett 12:1394-1404

Chisholm C, Lindo Z, Gonzalez A (2011) Metacommunity diversity depends on connectivity and patch arrangement in heterogeneous habitat networks. Ecography 34(3):415-424. https://doi.org/10.1111/j.1600-0587.2010. 06588. $\mathrm{x}$

Cordingley JE, Newton AC, Rose RJ, Clarke RT, Bullock JM (2015) Habitat fragmentation intensifies trade-offs between biodiversity and ecosystem services in a heathland ecosystem in southern England. PLoS ONE 10:1-15

Costanza R, D'Arge R, de Groot R, Farber S, Grasso M, Hannon B, Limburg K, Naeem S, O’Neill RV, Paruelo J, Raskin RG, Sutton P, van den Belt M (1997) The value of the world's ecosystem services and natural capital. Nature 387:253-260

Cox DTC, Inger R, Hancock S, Anderson K, Gaston KJ (2016) Movement of feeder-using songbirds: the influence of urban features. Sci Rep 6:37669

Cox DTC, Shanahan DF, Hudson HL, Plummer KE, Siriwardena GM, Fuller RA, Anderson KA, Hancock S, Gaston KJ (2017) Doses of neighborhood nature: the benefits for mental health of living with nature. Bioscience 67:147-155

Dakos V, Quinlan A, Baggio JA, Bennett E, Bodin Ö, BurnSilver S (2015) Principle 2-manage connectivity. Principles for building resilience: sustaining ecosystem services in social-ecological systems. Cambridge University Press, Cambridge, pp 80-104

Dickson BG, Albano CM, Anantharaman R, Beier P, Fargione J, Graves TA, Gray ME, Hall KR, Lawler JJ, Leonard PB, Littlefield CE, McClure ML, Novembre J, Schloss CA, Schumaker NH, Shah VB, Theobald DM (2019) Circuittheory applications to connectivity science and conservation. Conserv Biol 33:239-249. https://doi.org/10.1111/ cobi. 13230

Eigenbrod F (2016) Redefining landscape structure for ecosystem services. Curr Landsc Ecol Rep 1:80-86 
ESRI (2017) ArcGIS 10.6. Environmental Systems Research Institute, Redlands

Field RD, Parrott L (2017) Multi-ecosystem services networks: a new perspective for assessing landscape connectivity and resilience. Ecol Complex 32:31-41

Gómez-Baggethun E, Barton DN (2013) Classifying and valuing ecosystem services for urban planning. Ecol Econ 86:235-245

Grafius DR, Corstanje R, Warren PH, Evans KL, Hancock S, Harris JA (2016) The impact of land use/land cover scale on modelling urban ecosystem services. Landsc Ecol 31:1509-1522

Grafius DR, Corstanje R, Siriwardena GM, Plummer KE, Harris JA (2017) A bird's eye view: using circuit theory to study urban landscape connectivity for birds. Landsc Ecol 32:1771-1787

Grafius DR, Corstanje R, Warren PH, Evans KL, Norton BA, Siriwardena GM, Pescott OL, Plummer KE, Mears M, Zawadzka J, Richards JP, Harris JA (2019) Using GISlinked Bayesian Belief Networks as a tool for modelling urban biodiversity. Landsc Urban Plan 189:382-395

Hanks EM, Hooten MB (2013) Circuit theory and model-based inference for landscape connectivity. J Am Stat Assoc 108:22-31

Kang W, Minor ES, Park CR, Lee D (2015) Effects of habitat structure, human disturbance, and habitat connectivity on urban forest bird communities. Urban Ecosyst 18:857-870

Karimi JD, Corstanje R, Harris JA (2021) Bundling ecosystem services at a high resolution in the UK: trade-offs and synergies in urban landscapes. Landscape Ecol 36:1817-1835. https://doi.org/10.1007/s10980-02101252-4

Lafortezza R, Davies C, Sanesi G, Konijnendijk C (2013) Green Infrastructure as a tool to support spatial planning in European urban regions. iForest - Biogeosci For 6:102-108

Landuyt D, Broekx S, Dhondt R, Engelen G, Aertsens J, Goethals PLM (2013) A review of Bayesian belief networks in ecosystem service modelling. Environ Model Softw 46:1-11

LaPoint S, Balkenhol N, Hale J, Sadler J, van der Ree R (2015) Ecological connectivity research in urban areas. Funct Ecol 29:868-878

Leitão AB, Miller J, Ahern J, McGarigal K (2006) Measuring landscapes: a planner's handbook. Island Press, Washington, DC

Maguire DY, James PMA, Buddle CM, Bennett EM (2015) Landscape connectivity and insect herbivory: a framework for understanding tradeoffs among ecosystem services. Glob Ecol Conserv 4:73-84

Marcot BG, Steventon JD, Sutherland GD, McCann RK (2006) Guidelines for developing and updating Bayesian belief networks applied to ecological modeling and conservation. Can J For Res 36:3063-3074

McClure ML, Hansen AJ, Inman RM (2016) Connecting models to movements: testing connectivity model predictions against empirical migration and dispersal data. Landsc Ecol 31:1419-1432

McGarigal K, Cushman SA, Ene E (2012) Fragstats v4: spatial pattern analysis program for categorical and continuous maps. Produced by the authors at the University of
Massachusetts, Amherst. http://www.umass.edu/landeco/ research/fragstats/fragstats.html

McPhearson T, Andersson E, Elmqvist T, Frantzeskaki N (2015) Resilience of and through urban ecosystem services. Ecosyst Serv 12:152-156

McRae BH, Beier P (2007) Circuit theory predicts gene flow in plant and animal populations. Natl Acad Sci USA 104:19885-19890

McRae B, Dickson BG, Keitt HK, Shah VB (2008) Using circuit theory to model connectivity in ecology, evolution, and conservation. Ecology 89:2712-2724

McRae B, Shah VB, Mohapatra TK (2013) Circuitscape 4 user guide. The Nature Conservancy, Arlington. http://www. circuitscape.org

Milton Keynes Council (2015) Find out more about Milton Keynes. In: Milt. Keynes Counc. http://www.miltonkeynes.gov.uk/jobs-careers/find-out-more-about-miltonkeynes. Accessed 4 Sept 2015

Mitchell MGE, Bennett EM, Gonzalez A (2013) Linking landscape connectivity and ecosystem service provision: current knowledge and research gaps. Ecosystems 16:894-908

Mitchell MGE, Bennett EM, Gonzalez A (2014) Forest fragments modulate the provision of multiple ecosystem services. J Appl Ecol 51:909-918

Mitchell MGE, Bennett EM, Gonzalez A (2015) Strong and nonlinear effects of fragmentation on ecosystem service provision at multiple scales. Environ Res Lett 10:1-12

Mitchell MGE, Suarez-Castro AF, Martinez-Harms M, Maron M, McAlpine C, Gaston KJ, Johansen K, Rhodes JR (2015) Reframing landscape fragmentation's effects on ecosystem services. Trends Ecol Evol 30:190-198

Ng CN, Xie YJ, Yu XJ (2013) Integrating landscape connectivity into the evaluation of ecosystem services for biodiversity conservation and its implications for landscape planning. Appl Geogr 42:1-12

Norsys Software Corp. (2018) Netica 6.05

Office for National Statistics (2013) 2011 census, Key Statistics for Built Up Areas in England and Wales (report). United Kingdom Office for National Statistics, London

Peiser RB, Chang AC (1999) Is it possible to build financially successful new towns? The Milton Keynes experience. Urban Stud 36:1679-1703

Plummer KE, Siriwardena GM (2018) Point count survey data for birds in the east of England, UK, in 2013. NERC Environmental Information Data Centre. (Dataset). https:// doi.org/10.5285/c4806e25-5325-4b01-806691a8fb55eb41

Rodríguez JP, Beard TD, Bennett EM, Cumming GS, Cork SJ, Agard J, Dobson AP, Peterson GD (2006) Trade-offs across space, time, and ecosystem services. Ecol Soc 11:28

SAS Institute Inc. (2018) JMP, Version 14.0.0. Cary, NC: SAS Institute Inc

Saura S, Pascual-Hortal L (2007) A new habitat availability index to integrate connectivity in landscape conservation planning: comparison with existing indices and application to a case study. Landsc Urban Plan 83:91-103

Saura S, Torné J (2009) Conefor Sensinode 2.2: A software package for quantifying the importance of habitat patches for landscape connectivity. Environ Model Softw 24:135-139 
Shanahan DF, Miller C, Possingham HP, Fuller RA (2011) The influence of patch area and connectivity on avian communities in urban revegetation. Biol Conserv 144:722-729

Sharp R, Tallis HT, Ricketts T, Guerry AD, Wood SA, ChaplinKramer R, Nelson E, Ennaanay D, Wolny S, Olwero N, Vigerstol K, Pennington D, Mendoza G, Aukema J, Foster J, Forrest J, Cameron D, Arkema K, Lonsdorf E, Kennedy C, Verutes G, Kim CK, Guannel G, Papenfus M, Toft J, Marsik M, Bernhardt J, Griffin R, Glowinski K, Chaumont N, Perelman A, Lacayo M, Mandle L, Hamel P, Vogl AL, Rogers L, Bierbower W, Denu D, Douglass J (2016) Integrated valuation of environmental services and tradeoffs (InVEST) 3.4.4 User's Guide. The Natural Capital Project, Stanford

Thompson PL, Rayfield B, Gonzalez A (2017) Loss of habitat and connectivity erodes species diversity, ecosystem functioning, and stability in metacommunity networks. Ecography (cop) 40:98-108

Tratalos J, Fuller RA, Warren PH, Davies RG, Gaston KJ (2007) Urban form, biodiversity potential and ecosystem services. Landsc Urban Plan 83:308-317

Van der Biest K, D'Hondt R, Jacobs S, Landuyt D, Staes J, Goethals P, Meire P (2014) EBI: An index for delivery of ecosystem service bundles. Ecol Ind 37:252-265. https:// doi.org/10.1016/j.ecolind.2013.04.006

Publisher's Note Springer Nature remains neutral with regard to jurisdictional claims in published maps and institutional affiliations. 